\title{
ILLUSIO: AQUÉM E ALÉM DE BOURDIEU
}

\author{
Pedro Paulo Oliveira
}

[...] Out, out, brief candle.

Life's but a walking shadow, a poor player

That struts and frets his hour upon the stage

And then is heard no more. It is a tale

Told by an idiot, full of sound and fury

Signifying nothing.

(Shakespeare, Macbeth, act 5, scene 5)

Neste artigo, utilizo a idéia de illusio como um ponto de partida para reflexões teóricas bastante específicas. Atitude condenada por seu formulador, que sempre deplorou o uso de conceitos para exercícios desta natureza. Creio que "o grande interesse de Bourdieu centrava-se em seu método", como assinalou Mary Douglas ou como asseverou Donald Broady. Ele não ofereceu uma teoria geral da sociedade, buscou, ao invés, fornecer elementos para a formação do conhecimento sociológico (Wacquant 1992:5). Seus conceitos e postulados são, antes de tudo, operacionais.

Diferentemente do habitus, campo ou violência simbólica, a idéia de illusio é pouco divulgada e não aparece como um conceito-chave que é rapidamente associado à obra do sociólogo francês. Penso, no entanto, que ela se liga umbilicalmente tanto à idéia de habitus quanto à de campo, tendo também uma associação, mais mediatizada e não tão direta, com a idéia de violência simbólica. Farei no final rápidas alusões aos vínculos entre a illusio e as duas primeiras idéias (campo e habitus).

A illusio não é um conceito exaustivamente definido, pois se trata, assim como as demais idéias de Bourdieu, de uma concepção modelada para a pesquisa e não para uma discussão teórica escolástica que ele considerava, conforme já mencionado, despropositada na sociologia. 
À primeira vista, dizer isto parece depreciar o esforço consumado em uma vasta e fértil obra. Na verdade, esta afirmação busca enfatizar exatamente a força de uma sociologia fecunda e bastante útil, que não se aventurava a definições esotéricas e complexas (ainda que seu estilo aparentemente hermético desestimule pássaros incautos), modeladas ao gosto de exegetas e glosadores que pululam no campo da reflexão social: teóricos triunfantes de sua superioridade em relação à "selvageria empírica", mobilizados por aquilo que ele chamava, em sua ironia cáustica, de "audácia sem rigor".

Minha intenção aqui não é reduzir Bourdieu. Quando se faz isto, efetua-se uma operação bastante comum: primeiro se reduzem seus "conceitos básicos": "campo é [...] (seguido de uma redução conceitual) e habitus é apenas [...] (formulação simplificada na seqüência)". Dizer que seus "conceitos" são antes de tudo operacionais é apontar para a imbricação destes com a pesquisa e a preocupação em descrever fenômenos sociais, coisa que ele conseguiu realizar com muita felicidade. Sua obra impressiona exatamente por esta capacidade.

Quanto à idéia de illusio, considero-a importantíssima e ao mesmo tempo de apreensão esquiva, ainda que muitos possam rapidamente, lendo o autor, encontrar uma simplificação e catalogá-la no rol dos produtos de um socioreducionismo sem interesse. Buscarei nos itens e parágrafos seguintes trabalhá-la de modo bastante peculiar, indo além, porém ficando muito mais aquém do próprio uso que dela fez o sociólogo francês, uma vez que não a utilizo onde ficaria feliz seu formulador: como instrumento heurístico para descrição dos fenômenos sociais. Não resta dúvida de que me presto aqui a realizar aquele trabalho de "comentador sedentário das idéias alheias" que Bourdieu deplorava. Aceito de antemão o veredicto de escrevinhador - plumitivo, disse ele, certa vez (Bourdieu 1996a:369) e reconheço, sem nenhuma ironia, sua recomendação como muito mais útil do que aquilo que começarei a efetuar nos parágrafos que seguem. Isso talvez seja suficiente para que possam me designar como não-bourdiano. De fato, não me sinto à altura das exortações do sociólogo francês. Pas de problème.

\section{Aquém filogenético: cultura em cena}

"A sociedade sempre paga a si mesma com a falsa moeda de seu sonho" (Mauss apud Bourdieu 1996b:7). Esse famoso dito de Marcel Mauss pode ser aplicado também ao agente humano, pois este, antes de ser sapiens, é, seguindo Cassirer (2001), um animal symbolicum que elabora fantasias, 
imagens, símbolos aos quais se prende, transformando-os nos princípios orientadores de sua conduta e comportamento. A arte de uma possível explicação para tal afirmação constitui o desdobramento de argumentos que este pequeno conjunto de parágrafos busca articular. Para iniciar o processo, recorro aqui a uma postulação de cunho típico de história natural formulada por Geertz no seu já clássico A interpretação das culturas.

Para Geertz, o homem é um animal singular porque os mecanismos de controle que guiam a orientação do comportamento dos agentes dessa espécie são determinados de modo extragenético. Combatendo a idéia de que a cultura só teria sido possível após um desenvolvimento exaustivo da aparelhagem biológica, em uma perspectiva seqüencial e estratigráfica entre a evolução física e o desenvolvimento cultural, ele argumenta que, ao invés de ter sido acrescentada "a um animal acabado ou virtualmente acabado, [ela] foi um ingrediente essencial na produção desse mesmo animal" (Geertz 1989:59).

Dois argumentos prévios são fundamentais para que possamos entender sua tese. Primeiro, a descoberta de que "a maior parte das mudanças biológicas que produziram o homem moderno (...) ocorreu no sistema nervoso central, e especialmente no cérebro", e também o fato de que "o homem é, em termos físicos, um animal incompleto, inacabado". Assim, "ele tem que aprender muitas coisas antes de poder funcionar" (Geertz 1989:58). Essa incompletude deve ser superada a partir dos planos, receitas, regras e instruções inculcados por meio do contato com os outros agentes adultos que irão instilar os padrões de comportamento cultural daquela coletividade em cada novo rebento que emerge em um mundo sócio-histórico específico.

Entre o padrão cultural, o corpo e o cérebro, foi criado um sistema de realimentação (feedback) positiva, no qual cada um modelava o progresso do outro, um sistema no qual a interação entre o uso crescente das ferramentas, a mudança da anatomia da mão e a representação expandida do polegar no córtex é apenas um dos exemplos mais gráficos. Submetendo-se ao governo de programas simbolicamente mediados para a produção de artefatos, organizando a vida social ou expressando emoções, o homem determinou, embora inconscientemente, os estágios culminantes do seu próprio destino biológico. Literalmente, embora inadvertidamente, ele próprio se criou (Geertz 1989:60).

Com tais formulações é impossível falar de uma natureza humana independente da cultura. O nosso sistema nervoso central desenvolveuse em interação com a cultura e tornou-se impossível para o agente hu- 
mano dirigir seu comportamento ou organizar sua experiência sem a orientação fornecida por "sistemas de símbolos significantes" que constituem e integram os mais variados arranjos culturais.

É a incompletude da aparelhagem biológica que transforma o homem em um animal maleável. Sua memória genética - isto é, seus instintos é mínima quando comparada a de outras espécies e isto o torna dependente de símbolos culturais, pré-requisitos de sua existência biológica, psicológica e social:

[...] sem os homens certamente não haveria cultura, mas, de forma semelhante e muito significativamente, sem cultura não haveria homens [...] Somos animais incompletos e inacabados que nos completamos através da cultura — não através da cultura em geral, mas através de formas altamente particulares de cultura: dobuana e javanesa, Hopi e italiana, de classe alta e baixa, acadêmica e comercial (Geertz 1989:61).

Assim, os homens são artefatos culturais.

A argumentação de Geertz tem vários méritos. Um dos mais destacáveis é constituir o ambiente cultural como parte integrante do agente humano em um sentido amplo, rechaçando argumentações de cunho sociobiológico que buscam explicar comportamentos sociais e que freqüentam e se instalam não apenas nos chavões de senso comum, mas também e inclusive, nas mentes mais eruditas. Para o interesse específico deste artigo funciona como um ponto de partida para que possamos entender as condições de emergência da illusio.

\section{Aquém ontogenético: psique adestrada}

Quando vista como um conjunto de mecanismos simbólicos para controle do comportamento, fontes de informação extra-somáticas, a cultura fornece o vínculo entre o que os homens são intrinsecamente capazes de se tornarem e o que eles realmente se tornam, um por um (Geertz 1989:64).

Tornar-se o que se é: eis um processo complexo que envolve interações sociais e o conjunto de influências e contingências recolhidas no percurso sociobiográfico de cada agente. O ponto de partida para esse desenvolvimento deve levar em conta a incompletude humana postulada por Geertz e as aberturas que cada agente humano traz em si em função de sua condição de animal simbólico. 
O novo ser que vem ao mundo emerge como uma mônada psíquica que será tratada por adultos socializadores. Os passos iniciais no processo de constituição desse agente humano podem ser elucidados com o recurso de alguns postulados psicanalíticos.

Freud, em seus Três ensaios sobre a sexualidade, fornece o ponto de partida para a explicação de tal processo. Na interpretação desse texto feita por Laplanche (1985), efetua-se uma distinção entre "instinto" e "pulsão", relevando-se a passagem de um substrato biológico para uma reapropriação deste, por meio da sexualidade, pelo animal humano. O psíquico torna-se a instância de mediação entre o bios (substrato biológico humano, corpo) e o socius ${ }^{1}$. Fundamental nessa interpretação é o conceito de "apoio" (anlehnung em alemão, étayage em francês) e com ele iremos resumir, com o risco de simplificar demais, uma complexa teoria de origem psicanalítica.

De início, vale destacar a distinção entre o conceito de Instinkt (instinto) e Trieb (pulsão) tal como o faz Laplanche (1985:18): "o Instinkt é um comportamento pré-formado, cujo esquema está hereditariamente fixado e que se repete segundo as modalidades relativamente adaptadas a um certo tipo de objeto". Já a pulsão se desenvolve apoiando-se em uma função corporal essencial à vida. Para entendermos melhor a distinção, peguemos o caso da oralidade. Inicialmente o bebê suga para se alimentar. O impulso é determinado pelo desequilíbrio humoral ou tecidual. O processo de sucção é a ponte entre a satisfação instintiva, sediada primordialmente no sistema digestivo, e o alvo, que é o alimento, no caso o leite. Do ponto de vista do Instinkt temos a seguinte seqüência: procura do mamilo, mamada, alívio da tensão e saciedade. Instinto satisfeito.

A formação da pulsão sexual se dá apoiando-se nesse processo, pois paralelamente à alimentação há a excitação dos lábios e da língua pelo mamilo, pelo fluxo do leite morno, que dá origem a um processo sexual. Familiarizada com o prazer, a criança tenta renovar o chupar, que vai se autonomizando até separar-se das necessidades de nutrição. Constituise então uma pulsão sexual oral que se torna independente da nutrição.

Por que isso acontece no humano? Resgatando os argumentos de Geertz, pode-se aventar a hipótese de que o desenvolvimento hiperbólico da função cerebral em razão das incitações culturais, fundamentais para a constituição dos agentes, autonomiza a capacidade de elaborações simbólicas humanas. Aquele ser biologicamente inacabado, completado pela cultura durante em média seis anos de cuidados contínuos dos outros agentes adultos, hipertrofia a "capacidade simbolizante cerebral". Isto é possível ao se pensar o fato de um exercício de interação com os fenômenos 
culturais que possibilitasse a emergência de algo tal qual uma libido simbolizante no agente, o que permitiria fazer com que as pulsões nele se desenvolvessem apoiando-se nos instintos e, a partir daí, se autonomizassem. Esta postulação vai ao encontro da idéia de que no homem a memória genética - ou seja, os instintos - não tem a última palavra no que tange ao comportamento dos agentes de uma cultura específica, pois são as pulsões que obtêm a primazia na conformação das ações e das condutas e elas, as pulsões, dependem dos arranjos culturais.

Outras pulsões também se desenvolvem apoiando-se em funções vitais. A escopofilia, por exemplo, derivaria de uma inclinação baseada na percepção ocular do mundo ${ }^{2}$. Apoiada na curiosidade natural dos agentes (fundamental para muitos símios e outros mamíferos, no sentido de prover uma adaptação mais adequada ao meio natural), torna-se "voyeurismo", quando o prazer em olhar ou ser olhado durante o ato sexual constitui a única fonte de prazer.

A pulsão pode, inclusive, ser apropriada para definir gostos e modelos de comportamentos distintivos. O exemplo do gourmet (ou do enólogo) ilustra o fato de que para alguns agentes não basta apenas ingerir alguns alimentos (ou bebidas). Cabe antes degustá-los, apreciá-los e aprová-los, retirando de sua condição privilegiada os lucros simbólicos de pertencer a uma casta em que o gosto refinado aparece como esprit de finesse (Bourdieu 1979).

Um corolário surpreendente presente nos Três ensaios de Freud é a idéia de que não se pode falar pura e simplesmente em perversão sexual, pois a pulsão sexual humana já é sempre uma perversão do instinto. O que varia é a sanção do socius em relação às diferentes pulsões sexuais, ou falando em sinônimos, às diferentes perversões do instinto, sendo então o sexo convencional também uma forma de perversão, ainda que sancionada e consagrada pelos valores hegemônicos da cultura. O instinto é sempre "pervertido" pela sexualização, pois esta última metaforiza alvos, desloca e interioriza objetos, constitui e concentra zonas erógenas no corpo, no espírito, na psique. A conexão entre o desenvolvimento das pulsões e sua sanção cultural é o primeiro passo para que se possa entender a idéia bourdiana de illusio.

A psique é esta instância que medeia a relação do bios com o socius e nela se joga todo o mistério humano, pois intermedeia o fluxo de significantes da cultura simbólica e mítica com o substrato biológico inevitável e concreto, fazendo refluir um no outro em um contínuo processo de imbricamento, necessário e fundamental para todos os agentes humanos. Pela capacidade essencial de fazer surgirem representações (Castoriadis 1982:324), sua condição primeva é aquela constituída por um vazio origi- 
nário que deve ser preenchido, fechado, coberto. Abertura ou fissura do processo biológico inacabado, ela se potencializa como fonte e vazio de representações em uma transitividade contínua entre processos essenciais vitais que conjugam nos humanos objetos materiais diversos (leite, brinquedos, instrumentos etc.) e interações com outros (mãe, adultos socializadores etc.).

Tal como no apoio das funções físicas que fazem surgir a sexualidade humana, a elaboração psíquica não é ditada pela ordem biológica nem tem liberdade absoluta em relação a esta. O corpo dado e geneticamente constituído (que nunca se mantém só nessa condição, pois a cultura dele se reapropria continuamente, como bem o sabia Marcel Mauss 1974) tem uma função menor para a formação psíquica. Mas se o corpo, nosso substrato biológico, nada traz às fantasias, ele permite que elas existam. De modo inverso ao pensamento de senso comum, a psique deve muito menos aos fatos somáticos, ainda que estes sempre deixem nela sua marca, do que aos fatos da cultura, instância continuamente invasiva e constitutiva de suas fantasias e de seus elementos imaginários.

A entrada no mundo social exigirá da mônada psíquica a quebra de um estado inicial que é o do autocentramento, a desmontagem de uma fantasia originária em que somos o centro de tudo, regidos apenas pelo princípio do prazer. Esta fantasia originária e narcísica terá importância fundamental durante todo o período de vida do agente. Forçosamente a psique deve promover a cisão dessa fantasia e reconhecer o mundo como a realidade, fonte de desprazer. A fantasia originária de centralidade fundamental será paulatina e, muitas vezes, bruscamente abalada pelo processo de socialização. Ao infante será imposta a realidade de que ele não se confunde com o seio bom que dá prazer. Há o mundo que não se modela aos seus desejos. Ele deve reconhecer a alteridade, o outro, e descobrir que ele pode ser bom ou mal: seio bom quando o satisfaz, mal quando não o atende (fantasias originárias da posição inicial de autocentramento). Há muitas implicações desses fatos com o processo de construção de identidade do agente.

A identificação não pode ser mais autista. No mundo social, ela tem que ser transitiva, isto é, identificação com o outro, com algo fora de mim.

\section{Illusio e sublimação}

Se pensarmos o conceito de sublimação, tal como sugerido por Castoriadis, como a passagem entre investimento autista em "outros" socialmente san- 
cionados, no qual a psique é forçada a substituir seus próprios objetos de investimento por outros suportados pelas instituições sociais, há de se pensar também em uma dessexualização da pulsão instaurada em uma intersecção não-vazia entre o mundo privado e o público, este último continuamente invadindo e constituindo o primeiro (Castoriadis 1982:356). Aliás, aqui a idéia de invasão não é negativa, já que a incompletude humana, refletida em um território psíquico constituído por fantasias imaginárias, a requer para a necessária constituição do agente symbolicum social.

Repressão e sublimação interagem para que repartições de energia de investimento libidinal entre representações antigas e novas sejam realizadas. Assim, o agente só se torna um agente social quando "pode sentir prazer em fabricar um objeto, em falar com os outros, em ouvir uma história ou um canto, em demonstrar uma teoria, em adquirir um saber" (Castoriadis 1982:358). Para Castoriadis, o processo bem-sucedido de socialização é aquele que tornou o agente capaz de elaborar representações sociais que são para ele fonte de prazer (Castoriadis 1982:359). O socius constituise por um conjunto de objetos e de processos - alvos de sublimação para cada agente - que são típicos, categorizados e complementares uns dos outros.

Ao final do processo de socialização, o agente encontra-se próximo de sua situação original. Deve poder elaborar representações sociais que são para ele fonte de prazer. Já conseguiu estabelecer alvos com os quais se identifica e que são socialmente reconhecidos e sancionados. O percurso deve ser aquele que leva do fantasiar livre, situando o prazer no autocentramento, ao fantasiar controlado pelas instituições e pelos valores típicos de um momento sócio-histórico particular (Castoriadis 1982:359). Ao socius caberá proporcionar aos agentes a possibilidade de encontrarem um sentido em suas práticas dentro das significações sociais instituídas.

A sublimação já sugerida e pouco explorada na obra de Freud encontra um desenvolvimento em Castoriadis que guarda relações de semelhança com a idéia de illusio em Bourdieu, ainda que os objetivos e os recursos teóricos mobilizados por estes autores sejam bastante diferentes.

\section{Illusio}

Esta palavra vem de ludus (jogo) e "poderia significar estar no jogo, estar envolvido no jogo, levar o jogo a sério. A illusio é estar preso ao jogo, preso pelo jogo, acreditar que o jogo vale a pena ou, para dizê-lo de maneira mais simples, que vale a pena jogar [...] Illusio [...] é dar importância a um 
jogo social, perceber que o que se passa aí é importante para os envolvidos, para os que estão nele [...] É 'estar em', participar, admitir, portanto, que o jogo merece ser jogado e que os alvos engendrados no e pelo fato de jogar merecem ser perseguidos; é reconhecer o jogo e reconhecer os alvos [...] Os jogos sociais são jogos que se fazem esquecer como jogos e a illusio é essa relação encantada com um jogo que é o produto de uma relação de cumplicidade ontológica entre as estruturas mentais e as estruturas objetivas do espaço social" (Bourdieu 1996c:139-140).

A discussão preliminar que envolveu postulados de história natural e interpretações de cunho psicanalítico começa a ser mais pertinente ainda quando o próprio Bourdieu indica que "uma das tarefas da sociologia é a de determinar como o mundo social constitui a libido biológica, pulsão indiferenciada, em libido social, específica [...] O trabalho de socialização da libido é, precisamente, o que transforma as pulsões em interesses específicos, interesses socialmente constituídos que apenas existem na relação com um espaço social no interior do qual certas coisas são importantes e outras indiferentes" (Bourdieu 1996c:141-142).

Ainda que reconheça a transformação da libido biológica em libido social como uma das tarefas a serem deslindadas pela sociologia, não há na obra do sociólogo uma preocupação em investigar como essa libido ou pulsão indiferenciada orienta-se na direção da constituição de uma illusio. Talvez tal lacuna possa legitimar o esforço da discussão, bem como a adequação de fazê-lo orientado por um paradigma de interpretação psicanalítica e, previamente, ainda indicar como a incompletude biológica do humano abre e até mesmo incita as possibilidades do surgimento de elaborações fantasísticas típicas dessa espécie que, distante do rationale, constitui-se como artífice, criador e criatura de formas simbólicas nas quais ele vive e se reproduz, reproduzindo-as.

Aos que sentirem um certo desconforto com aproximações psicanalíticas para abordar uma idéia do sociólogo francês é bom lembrar que ele próprio chegou a recomendar essa aproximação em passagens de sua obra. Notadamente em Méditations pascaliennes, a aproximação da socioanálise com a psicanálise é explícita:

pode-se dizer, indiferentemente, ou que os agentes tiram partido das possibilidades oferecidas por um campo no intuito de exprimirem e de saciarem suas pulsões e desejos, eventualmente sua neurose, ou que os campos utilizam as pulsões dos agentes constrangendo-os à submissão ou à sublimação, fazendo-os se dobrarem diante das estruturas e das finalidades que lhe são imanentes. De fato, os dois efeitos ocorrem em cada caso, sem dúvida, em proporções desiguais, conforme os 
campos e os agentes e, desse ponto de vista, poder-se-ia descrever cada forma singular de um habitus específico (de artista, de escritor ou de erudito, por exemplo) como uma 'formação de compromisso' (no sentido de Freud) (Bourdieu 1997:198).

No mesmo texto, Bourdieu deplora as distâncias entre a sociologia e a psicanálise: “a forma originária da illusio é o investimento no espaço doméstico, lugar de um processo complexo de socialização sexual e de sexualização do social. E a sociologia e a psicanálise deveriam unir seus esforços (mas para isso seria necessário que elas conseguissem superar suas prevenções mútuas) para analisarem a gênese do investimento em um campo de relações sociais, assim constituído em objeto de interesse e de preocupação, no qual a criança se encontra cada vez mais envolvida e que constitui o paradigma e também o princípio de investimento no jogo social. Como se opera a passagem - descrita por Freud, de uma organização narcísica da libido, na qual a criança toma a si mesma (ou o seu próprio corpo) como um objeto de desejo - para um outro estado no qual ela se orienta em direção a uma outra pessoa, aderindo assim ao mundo de "relações de objeto" sob a forma do microcosmo social originário e dos protagonistas do drama que aí se joga" (Bourdieu 1997:199)?

Tais passagens deixam claro que, para o autor, as análises sociológica e psicanalítica são perspectivas reciprocamente auxiliares e uma jamais prescinde da outra quando se trata de investigar a emergência e a constituição da illusio nos agentes.

\section{Illusio além}

Bourdieu menciona o fato de que existem alvos, apostas, capitais, prêmios que orientam a organização dos microcosmos sociais que chama de campo. Do ponto de vista macrossocial, o espaço social global de uma coletividade pode instituir apostas, orientações, valores e demais elementos a estes associados que bem poderiam fundamentar a base de uma illusio coletiva (derivada daquilo que Castoriadis chama de significações sociais imaginárias). Não se devem esquecer as fissuras e as contradições entre objetos e apostas diferenciadas que integram todas essas possíveis illusios coletivas. Sua composição poderia ser vista como um lugar simbólico de sentido estruturante que estabelece padrões de possibilidade de constituição de illusios subjetivas, formuladas pelos agentes, e que se organizam em torno de lugares imaginários de sentido estruturante. 
Por que falar aqui em sentidos estruturantes seja para o lugar simbólico, portanto social, coletivo, seja também para o lugar imaginário, subjetivo, característico do agente? Porque se pensa aqui na illusio como uma forma de pulsão que metaforiza alvos, que desloca e recria objetos, que estipula metas, que concentra interesses, enfim, que direciona os esforços explícitos e implícitos de uma cultura que hierarquiza os seus valores enquanto lugares simbólicos. Para o agente ocorre o mesmo em escala subjetiva, portanto imaginária, orientando dessa forma condutas e comportamentos que possam atingir alvos, metas, objetos retirados do campo social, deslocados muitas vezes e necessariamente interiorizados por ele. A illusio subjetiva é aqui uma "formação de compromisso" socialmente sancionada, em que a busca identitária da fantasia originária de autocentramento se refaz, intermediada agora por objetos culturalmente valorizados. Em Bourdieu, tais objetos aparecem como apostas e prêmios em uma estrutura de jogo que orienta a ação subjetiva.

Fissuras e contradições na composição da illusio coletiva explicitamse na riqueza e na diversidade de possibilidades expressadas em conflitos e dinâmicas variados que retroagem uns sobre os outros, desencadeando mudanças contínuas na tessitura social.

Da mesma forma, illusios subjetivas são atravessadas por elementos contraditórios de constituição fantasística. Isto pode se expressar em habitus divididos, flutuantes e variáveis (Bourdieu 1997:79), resultados de lugares imaginários conflitantes. Assim como o agente busca recuperar a condição de primazia na fantasia do autocentramento originário a partir dessa busca orientada pelos objetos, pelas apostas e pelos prêmios muitas vezes conflitantes, assim também a cultura pode instituir valores simbólicos que se incompatibilizam. Desta dinâmica conflitiva orientada para a sustentação - seja da fantasia originária de completude e autocentramento no agente, seja da preservação e da unicidade de valores na cultura - emerge a trama da história, que não pode ser determinada $a$ priori e nem por isso ser vista como não-razoável e impensável a posteriori. Daí também deriva o fato de as ações humanas não serem nem o produto puramente aleatório de um indeterminado a priori e nem uma determinação racionalmente recuperável em uma descrição exaustiva dos fenômenos sociais.

Só se pode aqui aludir ao fato de que a illusio está associada de modo inextrincável às idéias de habitus e campo. Impossível desenvolver as razões desse fato neste curto artigo, a não ser realizando algumas alusões que mereceriam maior aprofundamento. Nesse sentido, pode-se dizer que o socius, em sua rede intrincada de relações complementares e 
contraditórias, condiciona a existência de campos variados, e o habitus, nessa perspectiva, seria a expressão de um bios subjetivo aberto e inacabado que se constitui na elaboração processual e incessante do socius, via illusio. Estrutura aberta que se refaz transformando-se, a mônada psíquica é a usina das elaborações imaginárias que se manifesta em illusios, em apostas, crenças, símbolos, fantasias. Todos estes elementos estão organizados e atendem às demandas inelutáveis de um bios, que necessita de certa quantidade de calorias diárias, e de um socius, que deve refazer seus símbolos, valores e instituições fornecendo tanto a organização social e coletiva do trabalho que permite atender às demandas do corpo, das ferramentas e das técnicas para a sua reprodução material - como os estímulos para que cada agente possa elaborar sentidos existenciais; sentidos estes que são as suas suturas imaginárias, as narrativas significativas que justificam sua vida e que diminuem a sua ansiedade ontológica, marcada pela falta de sentido fundante desse ser louco que é o animal symbolicum, misto de um bios inacabado e de um sócio-histórico particular e determinado.

A illusio é um jogo social levado a sério - fantasia subjetiva coletivamente sancionada, calcada em uma metafísica da distinção, pois para ser o centro do mundo devemos ser reconhecidos como distintos, tendo algum valor, alguma honra e dignidade frente a nós mesmos e aos demais. As instituições, ou os campos, através dos atos da constituição de seus prêmios e de alvos estabelecidos, realizam um verdadeiro milagre: "eles conseguem fazer crer aos indivíduos consagrados que eles possuem uma justificação para existir, ou melhor, que sua existência serve para alguma coisa" (Bourdieu 1996d:106). Proclamados como dignos de tal honraria e autorizados a receberem os lauréis da glória estarão aqueles que melhor vivenciarem esse jogo como algo sério, efetivo, aqueles que fantasiarem e experienciarem sua illusio em um grau de adesão e investimento libidinal o mais alto possível.

Para os demais, entre os quais este plumitivo que aqui se anuncia, para aqueles que buscam entender a illusio tal como ela foi aqui pensada, fica em destaque a idéia da incompletude, do interminável, do homem como ser cindido, fissurado, incompleto, Sísifo que sobe o morro e sabe que jamais o movimento terminará: ao fim da subida, novas descidas. Lembro-me de Hume sugerindo, por meio de um personagem, que os deuses aparentemente nos abandonaram (Hume 1992). Em alguns momentos, ei-nos conscientes deste fato, alertas para a orfandade divina e para o sem-fundo, o abissal que nos define. Mas a mônada psíquica, hipertrofiada desde o início pelo traquejo inevitável com símbolos significantes, imagina, inventa, canaliza energias para a constituição de 
illusios que se apóiam nos objetos socialmente elaborados (religare, always!: nossa tarefa). Reinventar-se, formular narrativas de sentido para as trajetórias de vida, elaborar transicionalidades, como diria Winnicott, para os nossos atos: eis as demandas do ser incompleto, que se apresentam em nossas vivências cotidianas. No estado de vigília, sonho, illusio. Parodiando um poeta: talvez de nossos restos e aflições, de nossas sombras e incompletudes surjam as apostas e as illusios que nos ajudem a escalar o cume dos dias, a vencer a faina das jornadas insanas, com o som e a fúria de um ator que interpreta tenazmente do canto de um palco qualquer para uma platéia vazia.

Recebido em 06 de agosto de 2004

Aprovado em 09 de agosto de 2005

Pedro Paulo de Oliveira é professor associado ao IUPERJ.

E-mail: <ppoliveira@iuperj.br>.

\section{Notas}

${ }^{1}$ Expressão retirada das formulações filosóficas de Deleuze e Guattari, O AntiÉdipo. Capitalismo e esquizofrenia, livro em que o termo aparece, mas os autores não se preocupam em conceituá-lo. A partir da leitura da obra, penso que eles tentaram, com esta formulação, escapar do desgastado conceito de sociedade, ao mesmo tempo em que o recuperam em um sentido mais amplo e genérico, transformando-o em algo mais processual e dinâmico. Utilizo-o em uma interpretação bastante pessoal, fazendo-o recobrir a idéia de um espaço-processual ou processo-espacializante dinâmico, intangível, mas efetivo, que compreende todos os objetos da vida social (pessoas, outros agentes, leis, instituições, símbolos, valores etc.).

${ }^{2}$ A preeminência do olhar sobre outros sentidos (audição, olfato, paladar e tato), na sociedade contemporânea, vem sendo abordada recentemente por autores da antropologia, da sociologia e da comunicação. 


\section{Referências bibliográficas}

BOURDIEU, Pierre. 1979. La distinction: critique sociale du jugement. Paris: Minuit. 1996a. As regras da arte: gênese e estrutura do campo literário. São Paulo: Companhia das Letras. . 1996b. "Marginalia. Algumas notas adicionais sobre o dom". Mana. Estudos de Antropologia Social, 2(2):720. 1996c. Razões práticas: sobre a teoria da ação. Campinas: Papirus. 1996d. A economia das trocas lingüísticas. São Paulo: Edusp. 1997. Méditations pascaliennes. Paris: Seuil.

CASSIRER, Ernst. 2001. Ensaio sobre o homem: introdução a uma filosofia da cultura humana. São Paulo: Martins Fontes.

CASTORIADIS, Cornelius. 1982. A instituição imaginária da sociedade. Rio de Janeiro: Paz e Terra.

DELEUZE, Gilles e GUATTARI, Felix. 1976. OAnti-Édipo: capitalismo e esquizofrenia. Rio de Janeiro: Imago.

FREUD, Sigmund. 1989. Três ensaios sobre a teoria da sexualidade e outros trabalhos. Edição Standard brasileira das obras psicológicas completas de Sigmund Freud, v. VII (1901-1905). Rio de Janeiro: Imago.

GEERTZ, Clifford. 1989. A interpretação das culturas. Rio de Janeiro: LTC.

HUME, David. 1992. Diálogos sobre a religião natural. São Paulo: Martins Fontes.

LAPLANCHE, Jean. 1985. Vida e morte em psicanálise. Porto Alegre: Artes Médicas.

MAUSS, Marcel. 1974. Sociologia e antropologia, vol. 2. São Paulo: EPU, EDUSP.
WACQUANT, Loïc. 1992. "The structure and logic of Bourdieu's sociology". In: P. BOURDIEU e L. WACQUANT. An invitation to reflexive sociology. Chicago, London: The University of Chicago Press. 
Resumo

O objetivo deste artigo é trabalhar a idéia de illusio tal como foi formulada por Bourdieu, enriquecendo-a com aportes teóricos da psicanálise e da reflexão desenvolvidos por autores distintos, como Clifford Geertz e Cornelius Castoriadis. A aproximação entre a reflexão sociológica cunhada como socioanálise, por Bourdieu, e a psicanálise pode ser efetuada no momento em que o conceito de illusio sugere uma aproximação efetiva com o conceito de sublimação, como buscam esclarecer os argumentos aduzidos no trabalho.

Palavras-chave: Illusio, Bourdieu, Socioanálise, Subjetividade, Psicanálise

\section{Abstract}

The aim of this article is to explore the idea of illusio as formulated by Bourdieu, enriching his notion with theoretical contributions from psychoanalysis and the thinking of such distinct authors as Clifford Geertz and Cornelius Castoriadis. The text argues that the sociological reflection dubbed socioanalysis by Bourdieu is compatible with psychoanalysis insofar as the concept of illusio displays close affinities with the concept of sublimation.

Key words: Illusio, Bourdieu, Socioanalysis, Subjectivity, Psychoanalysis 